\title{
BENDING CHARACTERISTICS OF LAMINATED WOOD COMPOSITES CONSTRUCTED WITH BLACK PINE WOOD AND ARAMID FIBER REINFORCED FABRIC
}

\author{
Abdurrahman Karaman \\ USAK UNIVERSITY \\ TURKEY \\ Mehmet Nuri Yildirim \\ Karabuk University \\ TURKEY \\ Onder Tor \\ Kastamonu University \\ TURKEY
}

(RECEIVED APRIL 2020)

\begin{abstract}
The aim of this study was to determine the 4-point bending strength and modulus of elasticity in bending of Black pine wood laminated materials reinforced with aramid fiber was bonded using epoxy or polyurethane glues separately. The samples were prepared in accordance with the TS 5497 EN 408 (2006). The results of the study determined that the highest value for static bending strength was found in the laminated wood samples $\left(83.94 \mathrm{~N} \cdot \mathrm{mm}^{-2}\right)$ that were prepared using inter-layer aramid fiber reinforced polymer (AFRP) and epoxy glue. The highest value of modulus of elasticity in bending was found in the samples prepared with inter-layer epoxy and AFRP (10311.62 N.mm-2). It was observed that the samples parallel to the glue line of the laminated material showed higher performance compared to those perpendicular to the glue line. The data obtained as a result of this study demonstrated that aramid fiber reinforced Black pine wood laminated materials can be used in the building industry as building materials.
\end{abstract}

KEYWORDS: Wood laminate, bending strength, modulus of elasticity, aramid fiber fabric, Black pine wood. 


\section{INTRODUCTION}

Wood as a natural material is vulnerable to attack by biotic agents, such as fungi or insects, and abiotic agents such as fire. The damage caused by these conditions, or new load or design alternations, can require an increase in the load-carrying capacity of the structure (Arriaga et al. 2002) which weaken its mechanical properties. To overcome the inferior mechanical properties of wood elements, fiber reinforced polymer (FRP) composite can be one of the solutions (Johns et al. 2000). Recently, FRP applications have started to be used in strengthening wooden structures, as in strengthening steel and reinforced concrete structures. In wooden structures, the element is sized according to the type of joining. The advantage of using high performance jointing systems is to use less volume of material with the same durability. Over time, wooden structures need to be strengthened due to reasons such as eliminating the damage caused by external factors and earthquakes, increasing the load bearing capacity of the building by restoration, preventing the early fatigue and breaks that may occur as a result of design mistakes (Alsheghri et al. 2019).

There are various strengthening methods applied during the production of laminated wood material. Metal materials as well as synthetic fibers are also used for strengthening purposes. According to Laufenberg et al. (1984), the first trials on strengthening wood or wood-based composite materials were conducted in the 1960s. Strengthening wood with synthetic fibers was first carried out by Wangaard (1964) and Biblis (1965). Among the studies in the literature regarding strengthening the majority have been conducted on polymer composites reinforced with glass fibers, carbon fibers and aramid fibers of wood materials.

The commonly utilized FRP composites as reinforcement for wood beams are carbon fiber reinforced polymer (CFRP), E-glass reinforced polymer (GFRP) and aramid fiber reinforced polymer (AFRP) (Tautanji 1999, Johns et al. 2000, Fiorelli et al. 2003, Lopez et al. 2003, Fiorelli et al. 2006, Dempsey et al. 2006, Fiorelli et al. 2011, Yahyaei et al. 2011, Alshurafa et al. 2012, Abu-Talib 2012, Osmannezhad et al. 2014, Yerlikaya 2014, Morales et al. 2015, Glisovic et al. 2016, Song et al. 2017, Yerlikaya 2019). Various experimental studies have shown that the reinforcement of wood material provides a wide range of improvement of load bearing capacity, elasticity and ductility (Amy et al. 2004, Buell et al. 2005, Li et al. 2009, Fiorelli et al. 2011, Komán et al. 2013, Nowak et al. 2013, Kánnár et al. 2014, Fedyukov et al. 2017, Essert et al. 2018, Krisztián et al. 2020).

Recently, the appearance on the market of new products such as carbon fiber or aramid and basalt fibers have increased the number of researches works on their implementation as reinforcement materials in timber elements (Romani et al. 2001, Borri et al. 2005). Aramid fiber is a well-known synthetic organic polymer fibre with the lowest specific gravity and highest tensile strength - to weight ratio of all reinforcing fibres. As such, aramid fibres are widely used in industry, especially in military and aerospace applications (Mallick 1993). Aramid fiber is one of the common fiber types used to hybridize carbon/epoxy composite due to its low density, high stiffness, high deformability, and high resistance to impact damage (Yayun et al. 2017). Aramid fibers have also been used to hybridize glass fiber and carbon fiber-reinforced epoxy composites for maintaining or improving stiffness and impact damage resistance (Gustin et al. 2005, Valenca et al. 2015, Priyanka et al. 2017).

The current research was outlined to address the creep response of solid wood and AFRP composites under constant load and environmental conditions, individually and in a combined mode (Plevris et al. 1995). A study by Yahyaei-Moayyed and Taheri (2011), defined the elasticity performance of Southern Scots pine and Douglas fir lumber beams strengthened with one-sided aramid fiber-reinforced polymer (AFRP) boards with short-term experimental and numerical 
research. The effect of the strengthening on the resistance of elasticity for the strengthened beams was also explained. An increase in AFRP-strengthened wood beams increased both the resistance and the hardness and effectively decreased the elastic deterioration of wooden beams (Yahyaei-Moayyed and Taheri 2011). Zhou et al. (2020), studied bond integrity of aramid, basalt and carbon fiber reinforced polymer bonded wood composites at elevated temperature. Cheon et al. (2020) studied on the stab resistance mechanism and performance of the carbon, glass and aramid fiber reinforced polymer and hybrid composites.

In the present study, aramid fiber reinforced polymer (AFRP), which is used to strengthen hose plastic and ballistic materials, was used in hydraulic systems that showed resistance under the influence of external forces. This study aimed to determine the four-point bending strength of Black pine (Pinus nigra) laminated wood materials reinforced with AFRP and the modulus of elasticity in bending. The utilization of AFRP in strengthening the Black pine laminated wood material constitutes to the originality of this study.

\section{MATERIAL AND METHODS}

The Black pine wood (Pinus nigra) used to prepare the test samples, was obtained randomly from timber enterprises in the Karabuk, Turkey. Careful attention was paid to the fact that the wood material used in experimental studies was not subjected to physical damage, mechanical impacts or biological harm.

Aramid fiber reinforced polymer (AFRP) was purchased from a private manufacturer (Dost Chemistry Tuzla, Istanbul) in Turkey. The aramid fibers are a class of heat-resistant and strong synthetic fibers and used in aerospace and military applications, for ballistic-rated body armor fabric and ballistic composites, marine hull reinforcement, and as an asbestos substitute. Aramid fibers possess a unique combination of high strength and modulus with low density and high elongation that results in improved impact resistance of the respective composites. Aramid fibers are the dominant reinforcement in fiber-reinforced polymers (FRP) for demanding applications in aerospace industry where excellent mechanical properties per unit weight are required (Denchev and Dencheva 2012). The density of the AFRP, which is a material that has high resistance to abrasion, impact, fracture, increased temperatures and low density, was $1.4{\mathrm{~g} \cdot \mathrm{cm}^{-3}}^{-3}$ (Dost Chemistry Tuzla, Istanbul)

Romabond polyurethane adhesive (Starwood Building Market, Usak, Turkey) was used. This polyurethane adhesive is a one component, fast curing, polyurethane based wood adhesive. Easy to apply, low viscosity and high bonding strength, water resistant. The technical properties of the glue are as follows: density $1.1 \pm 0.02 \mathrm{~g}^{\mathrm{c}} \mathrm{cm}^{-3}$, viscosity $\left(25^{\circ} \mathrm{C}\right) 4500 \pm 500 \mathrm{cp}, \mathrm{pH}$ value 3 , gluing time $20^{\circ} \mathrm{C}, 30 \mathrm{~min}$ in $65 \%$ relative humidity conditions (Romabond, 2018). Epoxy glue ( $\mathrm{L} 160 / \mathrm{H} 160)$ is a two-component adhesive that provides great adhesion to wood materials and is an epoxide that reaches the desired mechanical strength extremely quickly. The technical properties of the glue are as follows: density $0.96-1.0 \mathrm{~g} \cdot \mathrm{cm}^{-3}$, viscosity $\left(25^{\circ} \mathrm{C}\right) 10-50 \mathrm{MPa}$, refractor index 1.520 , gluing time $25^{\circ} \mathrm{C}, 45 \mathrm{~min}$ in $65 \%$ relative humidity conditions, as recommended by the manufacturer (Dost Chemistry, Tuzla, Istanbul) in Turkey.

\section{Preparation of the test samples}

$5 \times 70 \times 1000 \mathrm{~mm}$ slats were acquired from Black pine timber using the mowing method in a circular saw machine. After being stacked, the slats were kept in an air-conditioned room of $20 \pm 2^{\circ} \mathrm{C}$ temperatures and $65 \pm 5 \%$ relative humidity conditions until they reached $12 \%$ humidity. The test samples were prepared in accordance with the TS 5497 EN 408 (2006). 
For the preparation of the sample's polyurethane (PU-D4) and epoxy resin (L160/H160) were used. AFRP was placed between the slats. To produce the control samples without reinforcement, the glue was applied to both surfaces of the wood slats in amount of $180-200 \mathrm{~g} \cdot \mathrm{m}^{-2}$. To create the AFRP reinforced test samples, the glue solution was applied to the solid bonding surfaces with a brush in amount of $180-200 \mathrm{~g} \cdot \mathrm{m}^{-2}$. The surfaces were glued and left to rest for 5-6 min (open time) and then pressed at $1.2 \mathrm{~N} \cdot \mathrm{mm}^{-2}$ for 8 hours (closed time). For the cold press lamination process the materials were cold pressed in a press machine with a pressure gauge suitable for both hot and cold press at $1.2 \mathrm{~N} \cdot \mathrm{mm}^{-2}$. The laminated wood material obtained after the pressing process was prepared with a wood processing machines in accordance with the dimensions specified in the standard (Fig. 1).
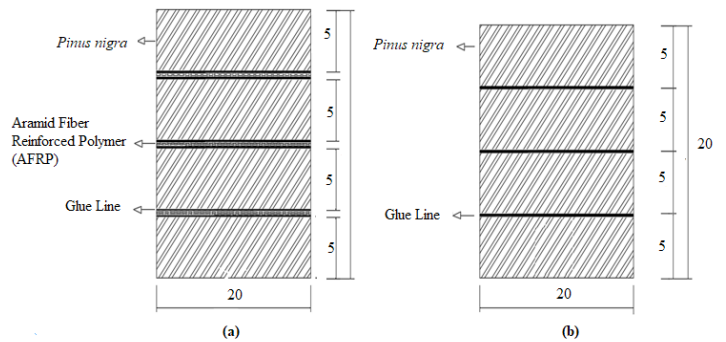

Fig. 1: General configuration of laminated wood material with (a) AFRP reinforced laminated wood (b) glue laminated wood (dimension $\mathrm{mm}$ ).

In total 80 samples were prepared, 10 replicates for each parameter. Prior to testing, all specimens were stored in a conditioning room maintained at $20 \pm 2^{\circ} \mathrm{C}$ and $65 \% \mathrm{RH}$ until moisture equilibrium was achieved.

\section{The four-point bending strength test}

The universal test device with a capacity of $50 \mathrm{kN}$ was applied to the prepared samples with static load parallel and perpendicular to the glue line. Static loading was determined with the four-point bending apparatus (Fig. 2).

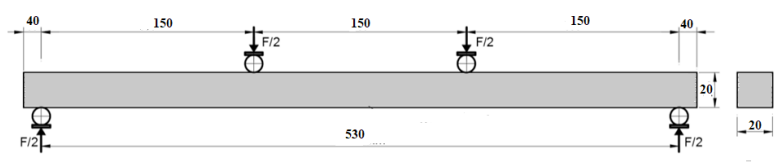

Fig. 2: Configuration of a four-point bending strength test (dimension $\mathrm{mm}$ ).

In this study, the TS $5497 \mathrm{EN} 408$ (2006) was taken into consideration. The test machine had a loading speed of $5 \mathrm{~mm} \cdot \mathrm{min}^{-1}$. The four-point bending strength, modulus of elasticity in bending and load bearing capacity were determined for the samples placed in such a way that the fulcrum point span was $360 \mathrm{~mm}$. The bending strength and modulus of elasticity were calculated according to the following equations:

Bending strength (N.mm-2) $=\frac{F \max . L}{b h^{2}}$
Modulus of elasticity $(\mathrm{N} . \mathrm{mm}-2)=\frac{\lambda^{3}\left(F_{2}-F_{2}\right)}{b_{1} h_{1}^{3}\left(W_{2}-W_{1}\right)}\left[\left(\frac{3 a}{4 \lambda}\right)-\left(\frac{a}{\lambda}\right)^{3}\right]$ 
where: Fmax is the maximum force at the time of rupture $(\mathrm{N}), \mathrm{L}$ is the span between supports $(\mathrm{mm}), \mathrm{b}$ is the width of the specimens $(\mathrm{mm})$, and $\mathrm{d}$ is the thickness of the specimens $(\mathrm{mm})$, $\lambda$ - measured length for determination of elasticity modulus $(\mathrm{mm}), b 1$ - sample width $(\mathrm{cm})$ (tangent measure), $h 1$ - sample height $(\mathrm{cm})$ (radial measure), $a$ - distance between loading point and nearest bearing $(\mathrm{mm}), F 2-F 1$ - increase of the load ratio on the straight line of the load deflection curve (N), Difference in deformation corresponding to W2 -W1=F2 -F1 (mm).

The statistical results, namely the arithmetic mean and standard deviation were calculated from the data acquired from the experiments. To determine the results of the experiments, multiple analysis of variance (ANOVA) was used to determine the effects of the factors on the values obtained for all the sample groups. Duncan's test was used to indicate the degree of significance if the interaction of the mutual strength of the factors was significant with a margin of error of $(\mathrm{p}<0.05) 5 \%$.

\section{RESULTS AND DISCUSSION}

\section{Bending strength}

Tab. 1 shows the statistical evaluation of the bending strength of both the control samples and the Black pine laminated wood. Tab. 2 and Tab. 3 show the results of the mean comparisons.

Tab. 1: Summary of mean bending strength values of laminated wood.

\begin{tabular}{|c|c|c|c|c|c|c|c|c|}
\hline & \multicolumn{8}{|c|}{ Bending strength (N.mm-2) } \\
\hline & \multicolumn{4}{|c|}{ Parallel to the glue line } & \multicolumn{4}{|c|}{ Perpendicular to the glue line } \\
\hline & \multicolumn{8}{|c|}{ Adhesive type } \\
\hline & \multicolumn{2}{|c|}{ Epoxy } & \multicolumn{2}{|c|}{ Polyurethane } & \multicolumn{2}{|c|}{ Epoxy } & \multicolumn{2}{|c|}{ Polyurethane } \\
\hline & Mean & Std. & Mean & Std. & Mean. & Std. & Mean & Std. \\
\hline Control sample & 79.06 & 3.6 & 75.92 & 3.4 & 75.02 & 2.2 & 73.03 & 1.7 \\
\hline Reinforced sample & 88.21 & 3.7 & 79.66 & 6.7 & 76.86 & 3.2 & 75.73 & 2.5 \\
\hline
\end{tabular}

When the bending strength values of the samples parallel to the glue line were examined it was found that the bending strength of the samples produced using epoxy glue without reinforcement was $79.06 \mathrm{~N} \cdot \mathrm{mm}^{-2}$, while the bending strength of the AFRP reinforced samples was $88.21 \mathrm{~N} \cdot \mathrm{mm}^{-2}$. On the other hand, it was observed that the bending strength of the samples produced using polyurethane glue without using the reinforcement was $75.92 \mathrm{~N} \cdot \mathrm{mm}^{-2}$, while the bending strength of the samples reinforced with AFRP was $79.66 \mathrm{~N} \cdot \mathrm{mm}^{-2}$. The evaluation of the bending strength values of the samples perpendicular to the glue line determined that the bending strength of the samples produced using epoxy glue without reinforcement was $75.02 \mathrm{~N} \cdot \mathrm{mm}^{-2}$ while the bending strength of the AFRP reinforced samples was $76.86 \mathrm{~N} \cdot \mathrm{mm}^{-2}$. It was determined that the bending strength of the samples produced using polyurethane glue without reinforcement was $73.03 \mathrm{~N} \cdot \mathrm{mm}^{-2}$ and the bending strength of AFRP reinforced samples was $75.73 \mathrm{~N} \cdot \mathrm{mm}^{-2}$. According to Tab. 2, the applied load differed depending on the position of the laminated wood material. It was found that the bending strength values of the samples parallel to the glue line were higher than those perpendicular to the glue line.

Tab. 2: Mean comparison of bending strength values in laminated wood materials.

\begin{tabular}{|l|c|c|}
\hline \multirow{2}{*}{} & \multicolumn{2}{|c|}{ Bending strength $\left(\mathbf{N} \cdot \mathbf{m m}^{-2}\right)$} \\
\cline { 2 - 3 } & Parallel to the glue line & Perpendicular to the glue line \\
\hline Reinforced sample & (83.94) A & (76.29) A \\
\hline Control sample & (77.49) B & (74.03) B \\
\hline
\end{tabular}


According to Tab. 3, the lowest bending strength value was obtained from the laminated wood samples produced without using the supporting material, and the highest bending strength value was obtained from the AFRP samples.

Tab. 3: Mean comparison of bending strength values of adhesive type in laminated wood materials.

\begin{tabular}{|l|c|c|}
\hline \multirow{2}{*}{ Adhesive type } & \multicolumn{2}{|c|}{ Bending strength $\left(\mathbf{N} . \mathbf{m m}^{-2}\right)$} \\
\cline { 2 - 3 } & Parallel to the glue line & Perpendicular to the glue line \\
\hline Epoxy glue & $(82.54) \mathrm{A}$ & $(75.94) \mathrm{A}$ \\
\hline PU-D4 & $(77.04) \mathrm{B}$ & $(74.38) \mathrm{B}$ \\
\hline
\end{tabular}

Various experimental studies show that the reinforcement of timber structures yields the improvement of load-bearing capacity, stiffness, and ductility, in a wide range, most likely owing to the organic nature of wood. Most studies report an increase of capacity $20 \%$ to $50 \%$ (Gentile et al. 2002, Triantafillou et al. 1992) or sometimes higher ( $\mathrm{Li}$ et al. 2009, Borri et al. 2005, Nowak et al. 2013), a negligible increase of stiffness (Amy et al. 2004, Buell et al 2005) or occasionally much higher (Borri et al. 2005, Fiorelli et al. 2011), and a general improvement of ductility.

AFRP reinforcement was successfully used for flexural strengthening of timbers; (II) the maximum load-carrying capacity of reinforced timber was dominant with the shear capacity of the AFRP layer/wood bond interface; (III) the flexural strength of southern yellow pine (SYP) and Douglas-fir (DF) wood species were improved by an average amount of $74 \%$ and 31\% (Yahyaei-Moayyed and Taheri 2011).

\section{Modulus of elasticity in bending}

The statistical evaluation of the results on modulus of elasticity in bending of the laminated wood materials, laminated stratified composite materials and solid wood materials are given in Tab. 4 and the results of the mean comparisons are given in Tab. 5 and Tab. 6. According to Tab. 4, when the modulus of elasticity in bending parallel to the glue line values are compared, it can be seen that the samples created using epoxy glue and AFRP gave maximum value, while those that used polyurethane glue and no reinforcement gave minimum value. It was observed that the elasticity values in bending perpendicular to the glue line were similar in the direction of the support with the reinforcement and AFRP.

Tab. 4: Summary of mean modulus of elasticity in bending values of laminated wood materials.

\begin{tabular}{|c|c|c|c|c|c|c|c|c|}
\hline & \multicolumn{8}{|c|}{ Modulus of elasticity in bending strength $\left(\mathrm{N} \cdot \mathrm{mm}^{-2}\right)$} \\
\hline & \multicolumn{4}{|c|}{ Parallel to the glue line } & \multicolumn{4}{|c|}{ Perpendicular to the glue line } \\
\hline & \multicolumn{8}{|c|}{ Adhesive type } \\
\hline & \multicolumn{2}{|c|}{ Epoxy glue } & \multicolumn{2}{|c|}{ PU-D4 } & \multicolumn{2}{|c|}{ Epoxy glue } & \multicolumn{2}{|c|}{ PU-D4 } \\
\hline & Mean & Std. & Mean. & Std. & Mean. & Std. & Mean. & Std. \\
\hline Control sample & 9101 & 197.2 & 8761 & 433.6 & 8604 & 224.6 & 8303 & 210.9 \\
\hline Reinforced sample & 10311 & 532.6 & 9116 & 723.1 & 9201 & 527.3 & 8756 & 606.1 \\
\hline
\end{tabular}

The difference between the groups in terms of the effects of variance sources on the elasticity modulus parallel and perpendicular to the glue line was found to be statistically significant in terms of material type $(\mathrm{p}<0.05)$. While glue variety was effective on the elasticity modulus of the samples parallel to the glue line, it was observed that there was no difference 
on the elasticity modulus of the samples perpendicular to the glue line. Furthermore, it was found that the binary interaction of material type and glue type, both perpendicular and parallel to the glue line, did not differ on the modulus of elasticity in bending. The results of the Duncan's test applied to determine the difference between the groups are given in Tab. 5 according to supporting material type and in Tab. 6 according to glue type.

Tab. 5: Mean comparison of modulus of elasticity in bending of supporting material type in laminated wood materials.

\begin{tabular}{|l|c|c|}
\hline \multirow{2}{*}{} & \multicolumn{2}{|c|}{ Modulus of elasticity in bending strength (N.mm ${ }^{-2}$ ) } \\
\cline { 2 - 3 } & Parallel to the glue line & Perpendicular to the glue line \\
\hline Reinforced sample & (9714) A & (8979) A \\
\hline Control sample & (8931) B & (8454) B \\
\hline
\end{tabular}

The results of the comparative Duncan's homogeneity test (Tab. 5), which was conducted to determine the significance of the type of supporting material on the modulus of elasticity in bending of the reinforced laminated wooden construction elements parallel and perpendicular to the glue line, the lowest value of the modulus of elasticity in bending both parallel to the glue line and perpendicular to the glue line was found in the laminated wooden construction elements produced without the reinforcement and the highest value in the samples in which AFRP was used. The homogeneity test results showed that the highest modulus of elasticity value in bending for samples parallel and perpendicular to the glue line was obtained in the laminated wood construction elements produced with epoxy glue, while the lowest value was found in the laminated wood construction elements produced with polyurethane glue (Tab. 6).

Consequently, several researchers considered the use of FRP an effective reinforcing agent for wood structural components. Wangard (1964) and Biblis (1965) studied the effect of bonding unidirectional fiberglass/epoxy-reinforced plastic to the compression and tension faces of wood cores of various species. Increases in modulus of elasticity (MOE) ranging from $20 \%$ to $50 \%$ using only $10 \%$ reinforcement by volume were reported. Osmannezhad et al. (2014) studied the behavior of glued laminated timbers and swan timbers for two different species (beech and poplar) was investigated under three-point bending. The results of MOR and MOE in three-point bending test, of the reinforced glulams with GFRP layers showed a slightly higher bending and shear capacities than the non-reinforced glue-laminated and sawn timbers. The best results were for reinforced glulam with four GFRP layers. It was expected increasing layers of GFRP layers improve mechanical properties.

Tab. 6: Mean comparison of modulus of elasticity in bending of adhesive type in laminated wood materials.

\begin{tabular}{|l|c|c|}
\hline \multirow{2}{*}{ Adhesive type } & \multicolumn{2}{|c|}{ Modulus of elasticity in bending strength (N.mm ${ }^{-2}$ ) } \\
\cline { 2 - 3 } & Parallel to the glue line & Perpendicular to the glue line \\
\hline Epoxy glue & (9707) A & (8903) A \\
\hline PU-D4 & (89379) B & (8530) B \\
\hline
\end{tabular}




\section{Fracture types}

The use of supporting materials between the layers of the produced reinforced laminated wood construction elements increased the bending strength both parallel to the glue line and perpendicular to the glue line. It can be said that using AFRP between layers as a supporting material reduced the brittleness between the layers due to glue, which in turn resulted in a more ductile structure, thus damping some of the energy that was generated as a result of loading. Furthermore, as shown in Fig. 3, it was determined that AFRP prevented the layers from separating from each other. As a result of the loading applied perpendicular to the glue line, the beginning of a breakage occurred in the wood material, and deformation developed in the glue layer and AFRP, and these deformations occurred between the layers. In the parallel applications to the glue line, deformations developed with the wood material glue layer and ARFP material and the fractures were in the form of zigzags. It was seen that the deformation zone formed in the loading perpendicular to the glue line covered more space in the loading parallel to the glue line. Fig. 4 shows the fractures caused by the loading parallel to the glue line.
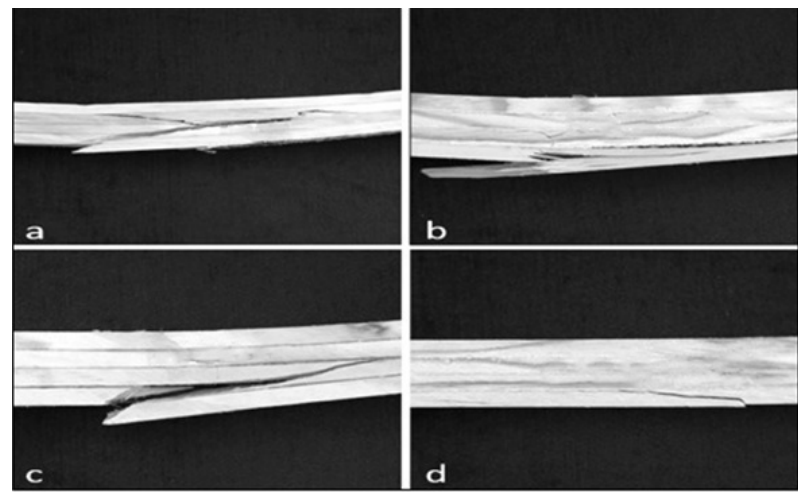

Fig. 3: Fracture types for bending test to perpendicular to the glue line; (a) Epoxy glue+No SMT, Epoxy+AFRP (b), PU-D4+ No SMT and (c) PU-D4+AFRP.

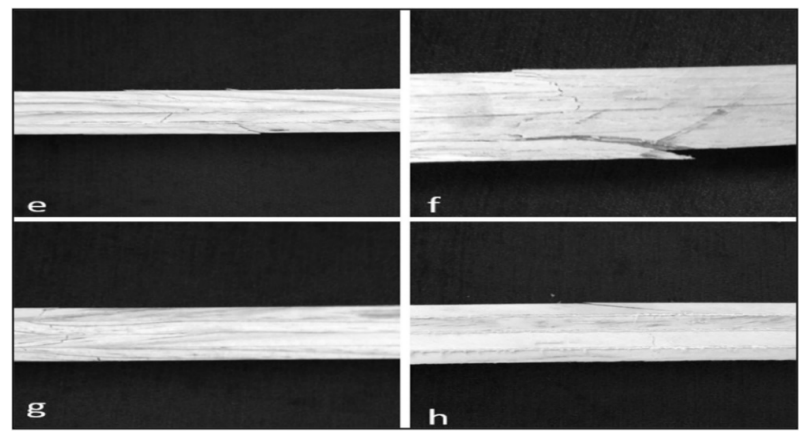

Fig. 4: Fracture types for bending test to parallel to the glue line; (e) Epoxy glue+No SMT Epoxy+AFRP (f), PU-D4 glue+No SMT and (b) PU-D4+AFRP. 


\section{CONCLUSIONS}

This study investigated, the modulus of elasticity in bending and four-point bending of wood laminated material reinforced by AFRP. Within this scope, AFRP was placed between four layers of slat prepared from Black pine (Pinus nigra) wood, which is extensively used in the manufacturing of furniture and building materials in Turkey, and epoxy and polyurethane glues were used to glue the layers. The control samples and samples supported with AFRP were statistically evaluated according to support material type, glue type and load application type. In terms of glue type, the highest bending strength value parallel to the glue line and perpendicular to the glue line was obtained from the epoxy glue, while the lowest bending strength value was obtained from the polyurethane glue. Additionally, the highest modulus of elasticity in bending value parallel to the glue line and perpendicular to the glue line was determined in the epoxy glue and the lowest in the polyurethane glue.

According to the evaluations made in terms of glue type, it was determined that using epoxy glue influenced increasing bending strength perpendicular to the glue line and parallel to the glue line. This could be explained by the fact that epoxy glue has a stronger chemical bond between wood lamellae than polyurethane glue. In spite of this, for the best results in terms of bending strength in applications parallel to the glue line and perpendicular to the glue line, it was determined that the laminated elements produced using epoxy glue reinforced with AFRP showed an increase in bending strength compared to the laminated elements produced without the reinforcement. The highest bending strength value parallel to the glue line and perpendicular to the glue line in terms of support material type was obtained from the AFRP support material, while the lowest bending strength value was obtained from the laminated elements produced without the reinforcement. In terms of glue line, the highest modulus of elasticity in bending value parallel and perpendicular to the glue line was determined in the AFRP material and the lowest value was determined in the laminated elements produced without the reinforcement. The reinforcement between the layers of the produced reinforced laminated wood construction elements increased the bending strength parallel and perpendicular to the glue line. It can be said that using AFRP between the layers reduced the brittleness caused by the glue between the layers, resulting in a more ductile structure, thus damping some of the energy that emerged as a result of the loading. This damping was found to be more in the applications perpendicular to the glue line. According to the experimental results in bending strength and modulus of elasticity in bending the AFRP supporting material increased strength of laminated wood material. As there were significant increases in the resistance properties of the material used as the intermediate filling material in the laminated wood materials, it is suggested that furniture and construction materials should have high strength properties.

\section{REFERENCES}

1. Abu-Talib, A.R., Ramadhan, A.A., Mohd Rafie, A.S., Zahari, R., 2013: Influence of cutout hole on multi-layer Kevlar-29/epoxy composite laminated plates. Materials and Design 43: 89-98.

2. Alsheghri, A., Akgul, T., 2019: Investigation of used of carbon fiber reinforced polymer sheets in joints of wooden structures. Academic Platform Journal of Engineering and Science 7(3): 406-413.

3. Alshurafa, S., Alhayek, H., Taheri, F., 2012: An investigation into the response of GFRPreinforced glue-laminated tudor arches. Hindawi Publishing Corporation Advances in Civil Engineering Vol. 2012, Article ID 357346, 11 pp. 
4. Amy, K., Svecova, D., 2004: Strengthening of dapped timber beams using glass fibre reinforced polymer bars. Canadian Journal of Civil Engineering 31: 943-55.

5. Arriaga, F., Peraza, F., Esteban, M., Bobadilla, I., García, F., 2002: Intervención en estructuras de Madera (Intervention in wooden structures). AITIM, $464 \mathrm{pp}$.

6. Biblis, E.J., 1965: Analysis of wood-fiberglass composite beams within and beyond the elastic region. Forest Product Journal 15(2): 81-89.

7. Borri, A., Corradi, M., Grazini, A., 2005: A method for flexural reinforcement of old wood beams with CFRP materials. Composite Part B 36(2): 143-153.

8. Buell, T.W., Saadatmanesh, H., 2005: Strengthening timber bridge beams using carbon fibre. Journal of Structural Engineering 131(1): 173-187.

9. Cheon, J., Lee, M., Kim, M., 2020: Study on the stab resistance mechanism and performance of the carbon, glass and aramid fiber reinforced polymer and hybrid composites. Composite Structures 234: 111690.

10. Dempsey, D.D., Scott, D.W., 2006: Wood members strengthened with mechanically fastened FRP strips. Journal of Composites for Construction 10(5): 392-398.

11. Denchev, Z.Z., Dencheva, N.V., 2012: Manufacturing and properties of aramid reinforced polymer composites. In: Synthetic polymer-polymer (ed. Bhattacharyya, D., Fakirov, S.)., Munich, Germany Pp 251-280, Hanser Publishers.

12. Essert, S., Rede, V., Svagelj, Z., 2018: The bending modulus of elasticity of subfossil elm wood. Wood Research 63(2): 239-248.

13. Fedyukov, V., Saldaeva, E, Chernova, M., 2017: Different ways of elastic modulus comparative study to predict resonant properties of standing spruce wood. Wood Research 62(4): 607-614.

14. Fiorelli, J., Dias, A.A., 2003: Analysis of the strength and stiffness of timber beams reinforced with carbon fiber and glass fiber. Materials Research 6(2): 193-202.

15. Fiorelli, J., Dias, A.A., 2006: Fiberglass-reinforced glulam beams: mechanical properties and theoretical model. Materials Research 9(3): 263-269.

16. Fiorelli, J., Dias, A.A., 2011: Glulam beams reinforced with FRP externally bonded: theoretical and experimental evaluation. Materials and Structures 44(8): 1431-1440.

17. Glišović, I., Stevanović, B., Todorović, M., Stevanović, T., 2016: Glulam beams externally reinforced with CFRP plates. Wood Research 61(1): 141-154.

18. Gustin, J., Joneson, A., Mahinfalah, M., Stone, J., 2005: Low velocity impact of combination Kevlar/carbon fiber sandwich composites. Composite Structures 69(4): 396- 406.

19. Hillermeier, K., 1984: Prospects of aramid as a substitute for asbestos. Textile Research Journal 54 (9): 575-580.

20. Johns, K.C., Lacroix, S., 2000: Composite reinforcement of timber in bending. Canadian Journal of Civil Engineering 27(5): 899-906.

21. Kánnár, A., 2014: Evaluation of glulam beams' performance in special environmental conditions. Wood Research 59(5): 803-812.

22. Komán, S., Fehér, S., Ábrahám, J., Taschner, R., 2013: Effect of knots on the bending strength and the modulus of elasticity of wood. Wood Research 58(4): 617-626.

23. Krisztián, A., Bertalan, B., 2020: Analysis of modulus of elasticity of spruce beams under bending with and without fibre reinforcement. Wood Research 65(1): 101-110.

24. Laufenberg, T.L, Rowlands, R.E, Krueger, G.P., 1984. Economic feasibility of synthetic fiber reinforced laminated slat lumber (LVL). Forest Product Journal 34(4): 15-22.

25. Li, Y.F., Xie, Y.M., Tsai, M.J., 2009: Enhancement of the flexural performance of retrofitted wood beams using CFRP composite sheets. Construction and Building Materials 23(1): 411-422. 
26. Lopez-Anido, R., Michael, A.P, Sandford, T.C., 2003: Experimental characterization of FRP composite-wood pile structural response by bending tests. Marine Structures 16: 257-274.

27. Mallick, P.K., 1993: Fiber-reinforced composites: materials, manufacturing, and design. 2nd edition, New York, USA: Marcel Dekker Inc, 74 pp.

28. Morales-Conde, M.J., Rodríguez-Liñán, C., Rubio-de Hita, P., 2015: Bending and shear reinforcements for timber beams using GFRP plates. Construction and Building Materials 96: 461-472.

29. Nowak, T.P., Jasienko J., Czepizak, D., 2013: Experimental tests and numerical analysis of historic bent timber elements reinforced with CFRP strips. Construction and Building Materials 40: 197-206.

30. Osmannezhad, S., Faezipour, M., Ebrahimi, G., 2014: Effects of GFRP on bending strength of glulam made of poplar (Populus deltoids) and beech (Fagus orientalis). Construction and Building Materials 51: 34-39.

31. Plevris, N., Triantafillou, T.C., 1995: Creep behaviour of FRP-reinforced wood members. Journal of Structural Engineering 121: 174-86.

32. Priyanka, P., Dixit, A., Mali, H.S., 2017: High-strength hybrid textile composites with carbon, kevlar and e-glass fibers for impact-resistant structures. a review. Mechanics of Composite Materials 53(5): 685-704.

33. Romani, M., Blab, H.J., 2001: Design model for FRP reinforced glulam beams, in: Proceedings of the International Council for Research and Innovation in Building and Construction (CIB). Working Commission W18 Timber Structures, Meeting Vol. 34, $10 \mathrm{pp}$.

34. Song, Y., Hong, S., Suh, J., Park, S., 2017: Strength performance evaluation of moment resistance for cylindrical-LVL column using GFRP reinforced wooden pin. Wood Research 62(3): 417-426.

35. Valenca, S.L., Griza, S., De-Oliveira, V.G., Sussuchi, E.M., De-Cunha, F.G.C., 2015: Evaluation of the mechanical behavior of epoxy composite reinforced with Kevlar plain fabric and glass/Kevlar hybrid fabric. Composites: Part B 70: 1-8.

36. Toutanji, H., Saafi, M., 1999: Performance of concrete beams prestressed with aramid fiber-reinforced polymer tendons. Composite Structures 44: 63-70.

37. TS 5497 EN 408, 2006: Timber structures. Structural timber and glue laminated timber. Determination of some physical and mechanical properties.

38. Wangaard, F.F., 1964: Elastic deflection of wood-fiberglass composite beams. Forest Product Journal 13(6): 256-260.

39. Yahyaei-Moayyed, M., Taheri, F., 2011: Experimental and computational investigations into creep response of AFRP reinforced timber beams. Composite Structures 93: 616-628.

40. Yayun, Z., Yuxin, S., Ruiyu, L., Qiran, S., Jiangtuo, F., 2017: Response of aramid honeycomb sandwich panels subjected to intense impulse loading by Mylar flyer. International Journal of Impact Engineering 104: 75-84.

41. Yerlikaya, N.C., 2014: Investigation of optimum dowel spacing for corner joints, which are reinforced with glass-fiber fabric in case-type furniture. Wood Research 59(1): 91-200.

42. Yerlikaya, N.C., 2019: Investigation of the differences between the glass-fiber fabric band and the edge bands in case-type furniture. Wood Research 64(6): 1087-1100.

43. Zhou, A., Oin, R., Chow, L.C., Lau, D., 2020: Bond integrity of aramid, basalt and carbon fiber reinforced polymer bonded wood composites at elevated temperature. Composite Structures 245: 112342 . 


$$
\begin{gathered}
\text { Abdurrahman Karaman* } \\
\text { Usak University } \\
\text { Banaz Vocational School } \\
\text { 6450o Usak } \\
\text { Turkey }
\end{gathered}
$$

*Corresponding author: abdurrahman.karaman@usak.edu.tr

$$
\begin{gathered}
\text { Mehmet Nuri Yildirim } \\
\text { Karabuk University } \\
\text { Safranbolu Vocational School } \\
78600 \text { Karabuk } \\
\text { Turkey } \\
\text { Onder Tor } \\
\text { Kastamonu University } \\
\text { Forestry Faculty } \\
\text { 37ioo Kastamonu } \\
\text { Turkey }
\end{gathered}
$$

